\title{
Analysis of P-Q and D-Q APF using Hysteresis and SPWM Techniques
}

\author{
Shivayogi Talagalamani ${ }^{1}$, Sandhya. $\mathbf{P}^{2}$ \\ M.Tech Student (Power Electronics), Dept of EEE, The Oxford College of Engineering Bengaluru, Karnataka, India ${ }^{1}$ \\ Associate Professor, Department of EEE, The Oxford College of Engineering Bengaluru, Karnataka, India ${ }^{2}$
}

\begin{abstract}
By the high-quality usage of power electronics devices which include rectifier, inverter, U.P.S, S.M.P.S, and speed drives and so on, many problems are introduced in power systems. One of such trouble is generation of current\& voltage harmonics inflicting distortion of load waveform, voltage variation, voltage depression, heating of system and many others. This paper is an attempt to mitigate the harmonics by using different control method for the Shunt A.P.F. The different control techniques used in the proposed performance analysis are the d-q method using PI controller with current hysteresis controller and PI controller with SPWM controller. The other set of controller technique is the p-q method using PI controller with current hysteresis controller and PI controller with SPWM controller. The simulation of proposed circuit is done by using MATLAB\& the results are tabulated and the performance evaluation is carried out.
\end{abstract}

Keywords: Shunt active power filter (SAPF), P-Q method, D-Q method, Current control, Total harmonics distortion.

\section{INTRODUCTION}

Power electronic switching device at the side of nonlinear loads reasons severe harmonic trouble in electricity tool. Main consequences of harmonics are over-heating, capacitor failure, resonance trouble, small energy component, overcapacity, communication interference and energy instability [1-2]. Therefore to enhance the overall performance, it is essential to remove harmonics from energy application device. One of the technique used for harmonics removal is using S.A.P.F, wherein a reference current is produced. S.A.P.F may be used with different current controller scheme together with D-Q technique, fuzzy control, P-Q technique, neural systems and so on[3-7], which are beneficial in eliminating powerful harmonic from energy device.

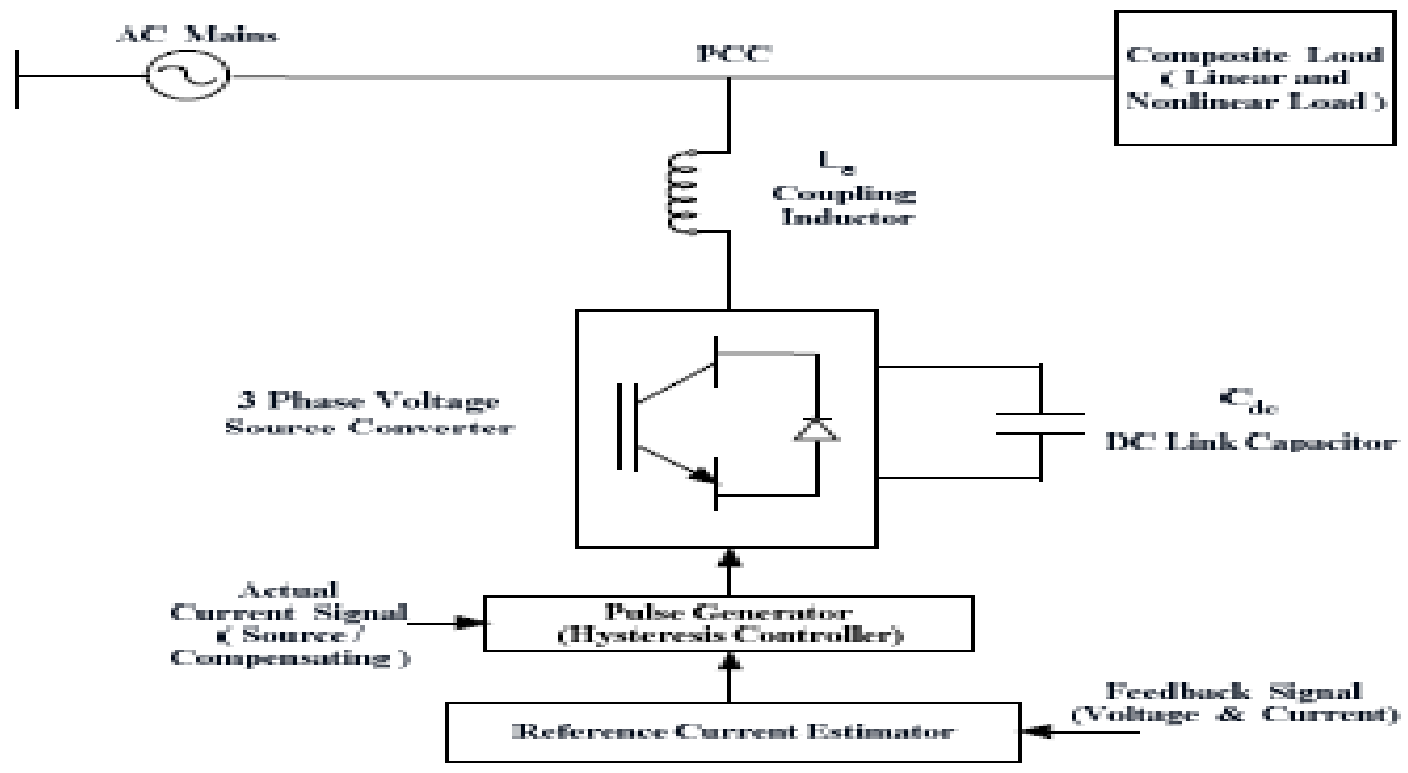

Fig.1. Basic Construction of a Shunt A.P.F

\section{DIFFERENT CONTROLLING STRATEGIES FOR SHUNT APF}

The different control strategies discussed here are p-q method, d-q method, current hysteresis controller and sinusoidal pulse width modulation (SPWM) and PI controller. 


\section{A. P-Q Technique}

The p-q theory is based on the set of instantaneous power in time domain. 3 phase voltage and current waveforms are transformed from the a-b-c coordinates to $\alpha-\beta$ coordinates and this theory is based on Clarke transformation.

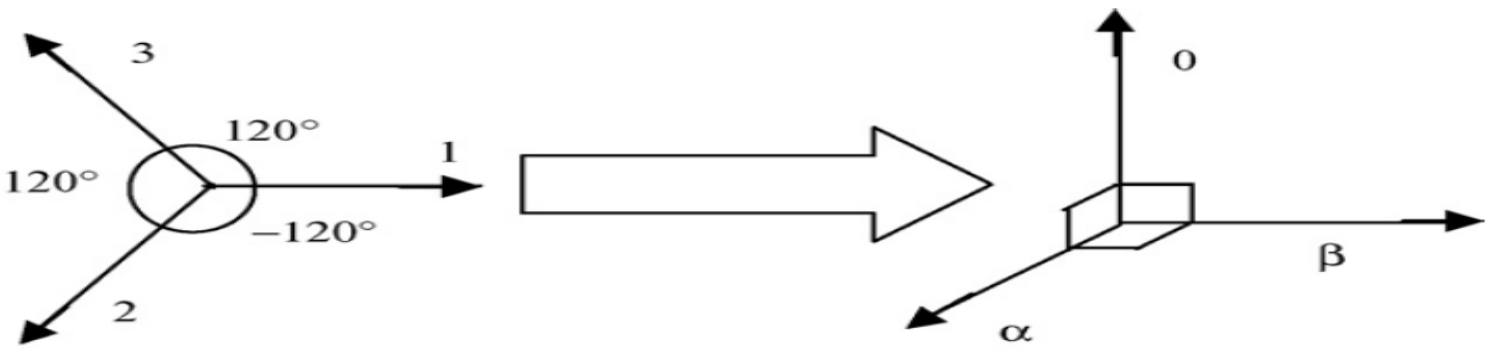

Fig.2. $0-\alpha-\beta$ reference system

$$
\begin{aligned}
& {\left[\begin{array}{l}
\mathrm{v}_{\alpha} \\
\mathrm{v}_{\beta}
\end{array}\right]=\sqrt{\frac{2}{3}}\left[\begin{array}{ccc}
1 & -\frac{1}{2} & -\frac{1}{2} \\
0 & \frac{\sqrt{3}}{2} & -\frac{\sqrt{3}}{2}
\end{array}\right]\left[\begin{array}{l}
\mathrm{v}_{\mathrm{sa}} \\
\mathrm{v}_{\mathrm{sb}} \\
\mathrm{v}_{\mathrm{sc}}
\end{array}\right]} \\
& {\left[\begin{array}{l}
\mathrm{i}_{\mathrm{l \alpha}} \\
\mathrm{i}_{\mathrm{l} \beta}
\end{array}\right]=\sqrt{\frac{2}{3}}\left[\begin{array}{ccc}
1 & -\frac{1}{2} & -\frac{1}{2} \\
0 & \frac{\sqrt{3}}{2} & -\frac{\sqrt{3}}{2}
\end{array}\right]\left[\begin{array}{l}
\mathrm{i}_{\mathrm{la}} \\
\mathrm{i}_{\mathrm{lb}} \\
\mathrm{i}_{\mathrm{lc}}
\end{array}\right]} \\
& {\left[\begin{array}{l}
\mathrm{p}_{\mathrm{l}} \\
\mathrm{q}_{\mathrm{l}}
\end{array}\right]=\left[\begin{array}{cc}
\mathrm{V}_{\alpha} & \mathrm{V}_{\beta} \\
-\mathrm{V}_{\beta} & \mathrm{V}_{\alpha}
\end{array}\right]\left[\begin{array}{l}
\mathrm{i}_{\mathrm{l} \alpha} \\
\mathrm{i}_{\mathrm{l}}
\end{array}\right]} \\
& {\left[\begin{array}{l}
\mathrm{i}_{\mathrm{c} \alpha} \\
\mathrm{i}_{\mathrm{c} \beta}
\end{array}\right]=\frac{1}{\mathrm{v}_{\alpha}^{2}+\mathrm{v}_{\beta}^{2}}\left[\begin{array}{cc}
\mathrm{v}_{\alpha} & -\mathrm{v}_{\beta} \\
\mathrm{v}_{\beta} & \mathrm{v}_{\alpha}
\end{array}\right]\left[\begin{array}{l}
\mathrm{p}_{\mathrm{c}} \\
\mathrm{q}_{\mathrm{c}}
\end{array}\right]} \\
& {\left[\begin{array}{l}
\mathrm{i}_{\mathrm{ca}} \\
\mathrm{i}_{\mathrm{cb}} \\
\mathrm{i}_{\mathrm{cc}}
\end{array}\right]=\sqrt{\frac{2}{3}}\left[\begin{array}{cc}
1 & 0 \\
-\frac{1}{2} & \frac{\sqrt{3}}{2} \\
-\frac{1}{2} & -\frac{\sqrt{3}}{2}
\end{array}\right]\left[\begin{array}{l}
\mathrm{i}_{\mathrm{sa}} \\
\mathrm{i}_{\mathrm{sb}}
\end{array}\right]}
\end{aligned}
$$

\section{B. D-Q Technique}

In D-Q technique, reference currents are produced from the d-q component of the nonlinear load, and this controlling technique is based on park transformation.

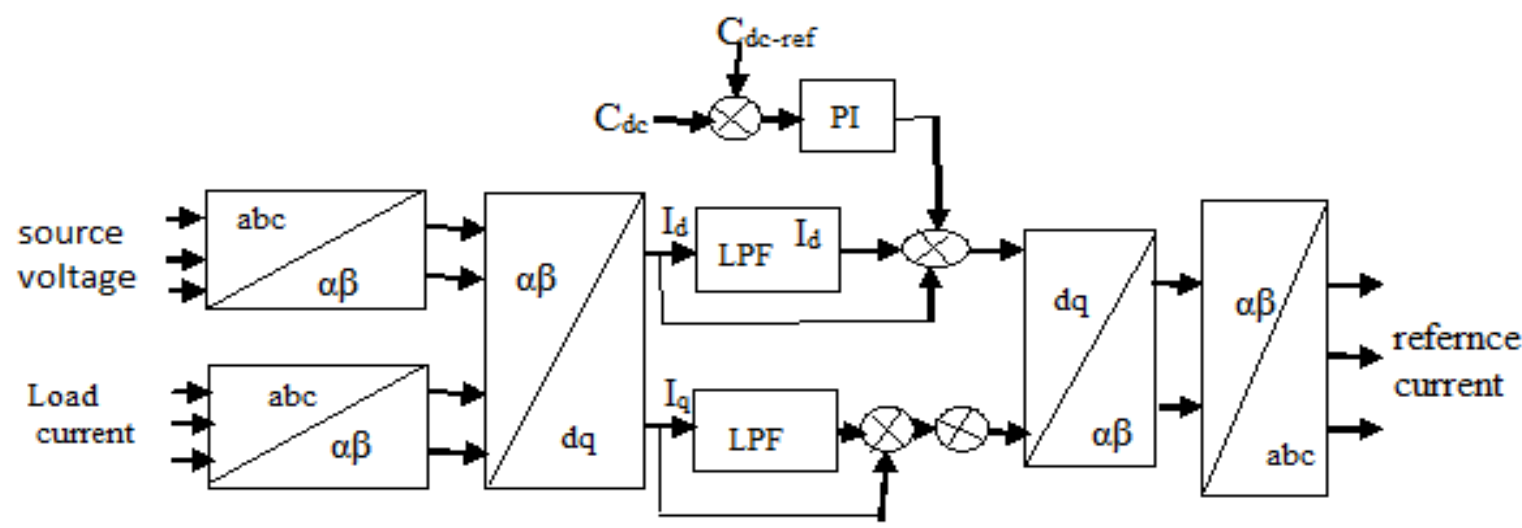

Fig.3. Controlling algorithm using d-q technique

The d-q load current are derived using the Park transformation.

$$
\left[\begin{array}{l}
\mathrm{i}_{\mathrm{ld}} \\
\mathrm{i}_{\mathrm{iq}}
\end{array}\right]=\frac{1}{\sqrt{\mathrm{v}_{\alpha}^{2}+\mathrm{v}_{\beta}^{2}}} \cdot\left[\begin{array}{cc}
\mathrm{v}_{\alpha} & \mathrm{v}_{\beta} \\
-\mathrm{v}_{\beta} & \mathrm{v}_{\alpha}
\end{array}\right] \cdot\left[\begin{array}{c}
\mathrm{i}_{\mathrm{l} \alpha} \\
\mathrm{i}_{\mathrm{l} \beta}
\end{array}\right]
$$




$$
\left[\begin{array}{l}
i_{c \alpha} \\
i_{c \beta}
\end{array}\right]=\frac{1}{\sqrt{v_{\alpha}^{2}+v_{\beta}^{2}}} \cdot\left[\begin{array}{cc}
v_{\alpha} & -v_{\beta} \\
v_{\beta} & v_{\alpha}
\end{array}\right] \cdot\left[\begin{array}{l}
i_{c d} \\
i_{c q}
\end{array}\right]
$$

C. Hysteresis Controller

It is used for producing the gating pulses for the converter. Fig 4 shows the hysteresis controller.

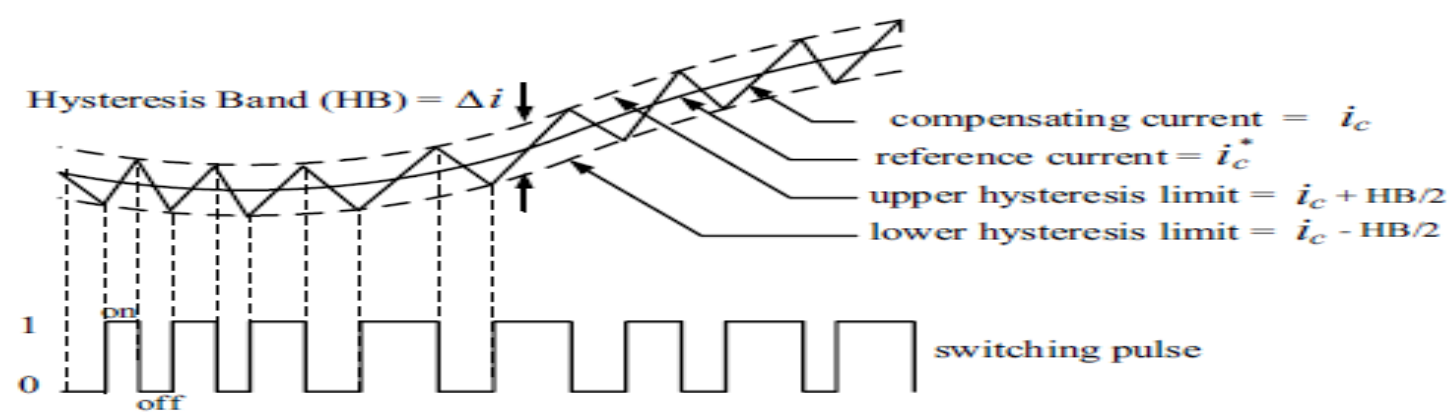

Fig.4. Hysteresis current controller

D. Sinusoidal Pulse width Modulation(SPWM)

Triangular carrier (TC): It compares the error within the output current with the fixed value and the fixed triangular wave.

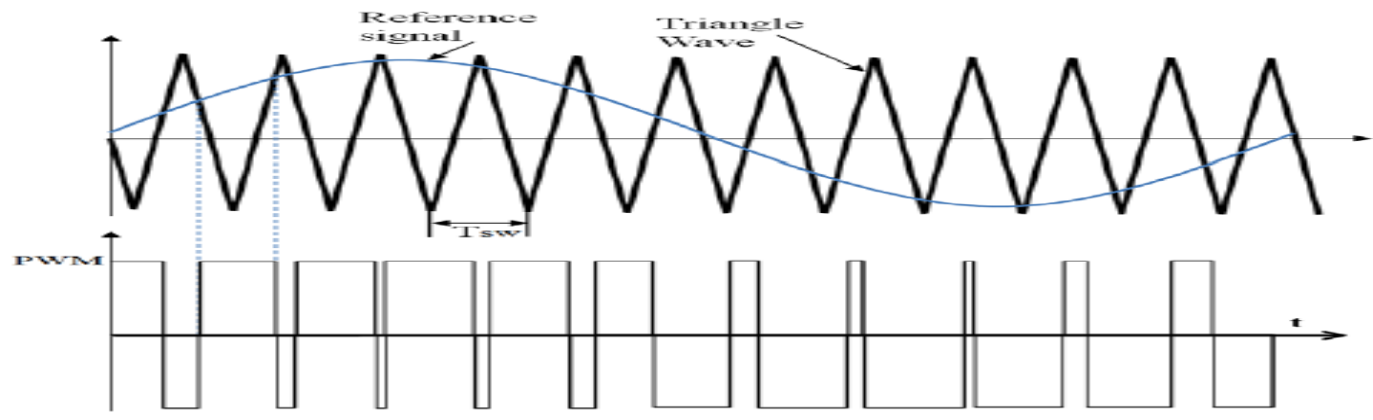

Fig.5. SPWM Technique (triangular carrier)

E. PI Controller

The figure 6 shows the construction PI controller. The circuit consists of P.I controller, ref. current\& hysteresis controller to produce the gating pulses.

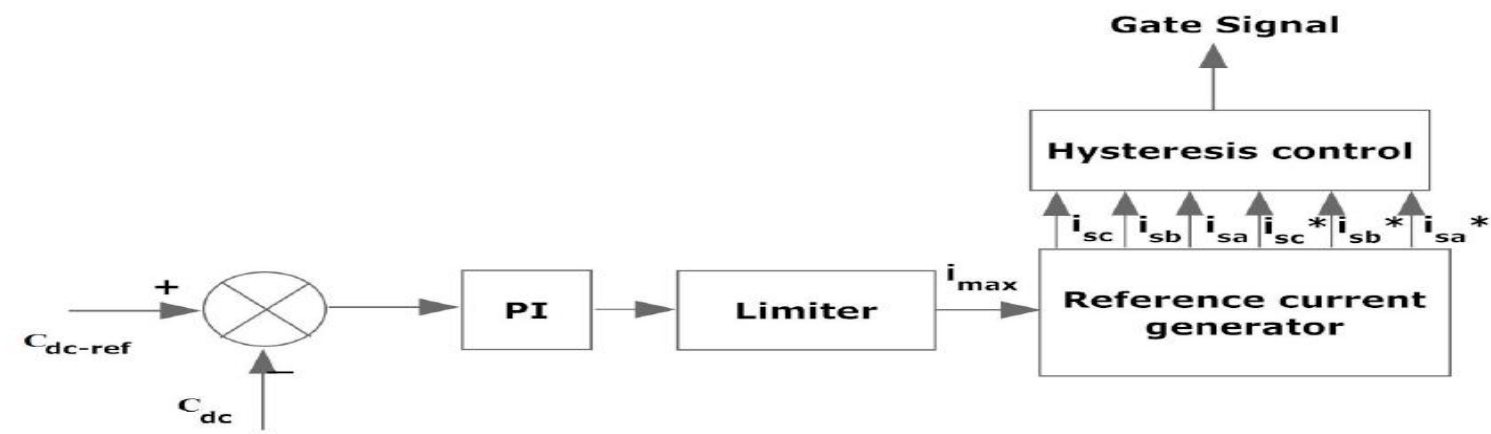

Fig.6. PI controller

\section{SIMULATION RESULTS AND DISSCUSSION}

To prove the cogency of the $\mathrm{p}-\mathrm{q}$ and $\mathrm{d}-\mathrm{q}$ techniques A.P.F using hysteresis \& spwm method, a well-known MATLAB/Simulink tool is used to show the results [8]. The circuit specification are given in table 1. 
IJIREEICE

\section{International Journal of Innovative Research in} Electrical, Electronics, Instrumentation and Control Engineering

ISO 3297:2007 Certified

Vol. 5, Issue 6, June 2017

Table.1 S.A.P.F parameter specification

- $\quad$ A.P.F Parameters

\begin{tabular}{|c|c|}
\hline Coupling Inductance & $9 \mathrm{Mh}$ \\
\hline Coupling Resistance & $1 \Omega$ \\
\hline DC link Capacitance & $1020 \mu \mathrm{F}$ \\
\hline Source inductance & $0.1 \mathrm{mH}$ \\
\hline Source resistance & $1 \Omega$ \\
\hline Load resistance & $1 \mathrm{k} \Omega$ \\
\hline Load inductance & $2 \mathrm{Mh}$ \\
\hline
\end{tabular}

A. Simulation circuit without filter

Figure 7.Shows the non-linear load without compensation.

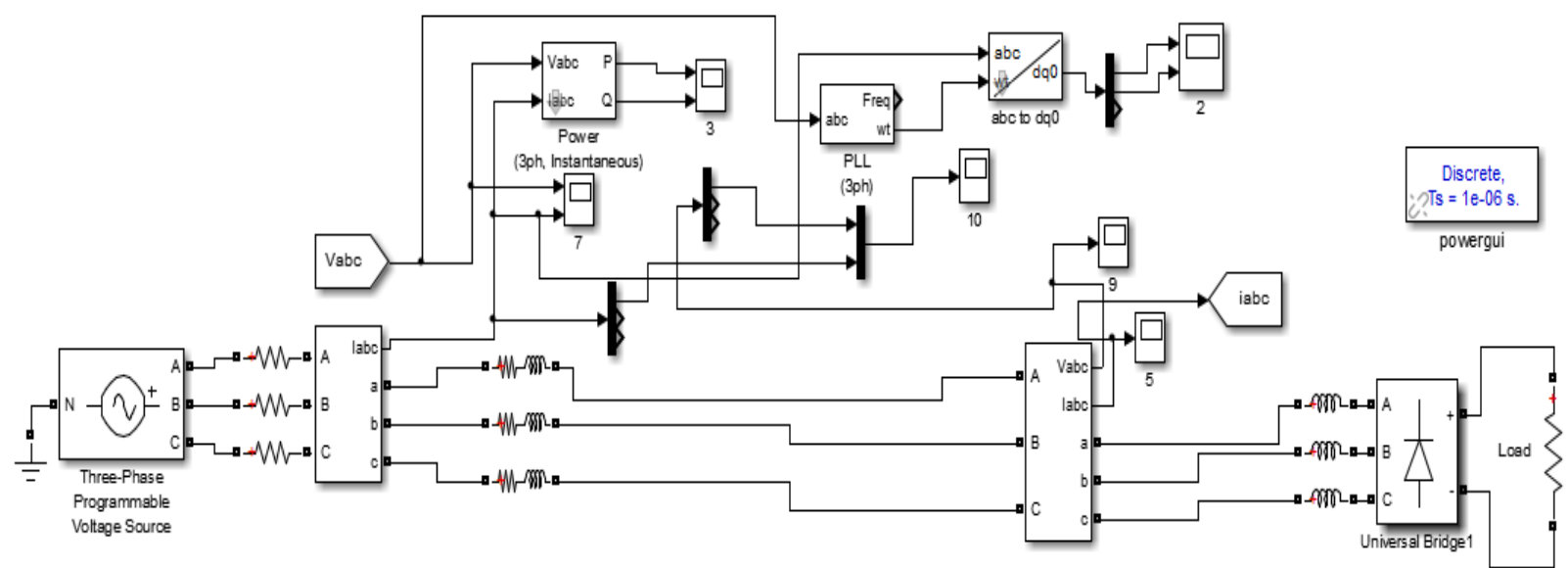

Fig. 7: Simulation circuit of the nonlinear load without compensation

(A)(i) Simulated output waveforms

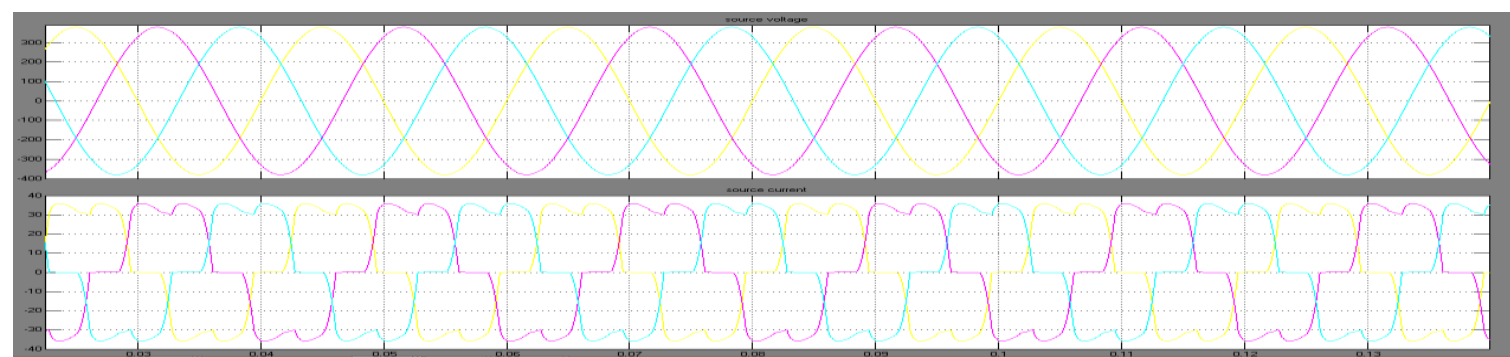

Fig. 7(a): 3 phase voltage and current waveform at grid side

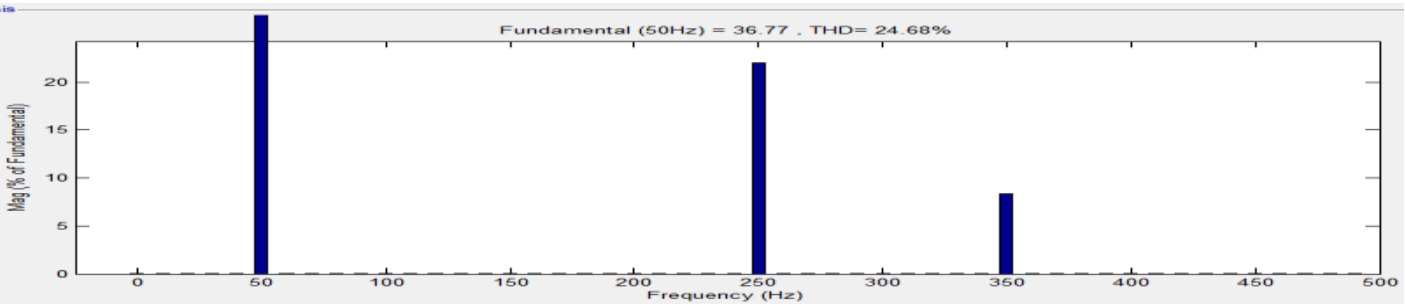

Fig. 7(b): current THD analysis

B. Simulation circuit with compensation using Current Hysteresis and PI with d-q technique

The hysteresis controller will compare the reference current with actual current and if the difference is positive the positive sequence switch will be on and similarly for the negative. The fig. 8 shows the complete simulation circuit diagram. 
International Journal of Innovative Research in Electrical, Electronics, Instrumentation and Control Engineering

ISO 3297:2007 Certified

Vol. 5, Issue 6, June 2017

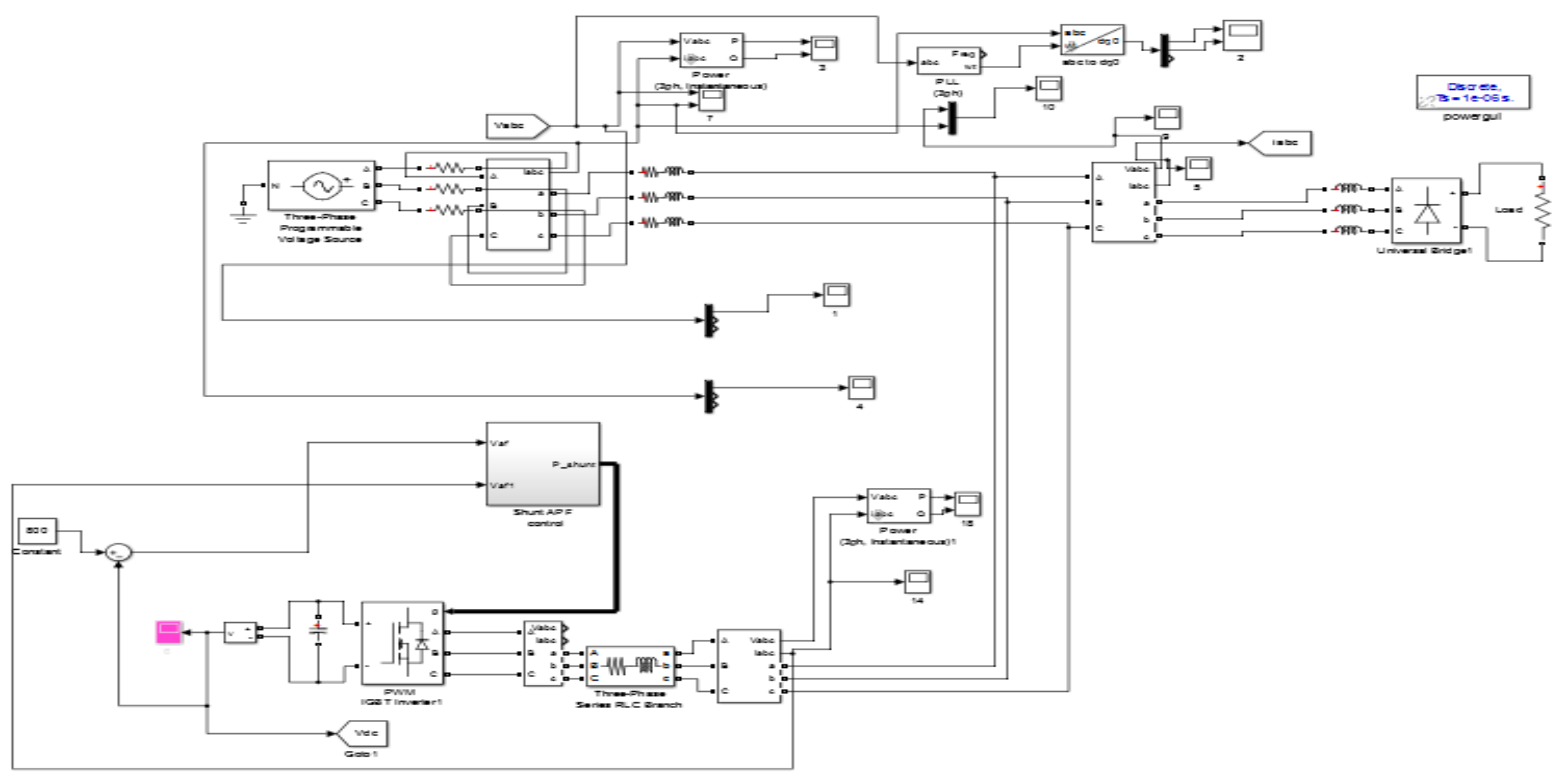

Fig. 8: Simulation circuit of current hysteresis and PI using d-q technique

(B)(i) Simulated output waveforms

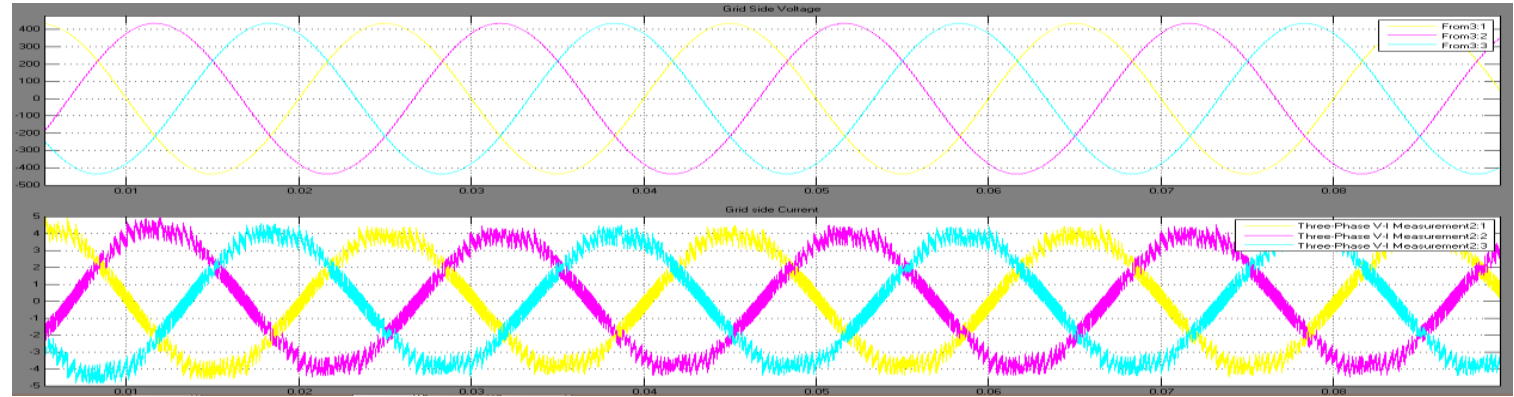

Fig. 8(a): 3 phase voltage and current waveform at grid side

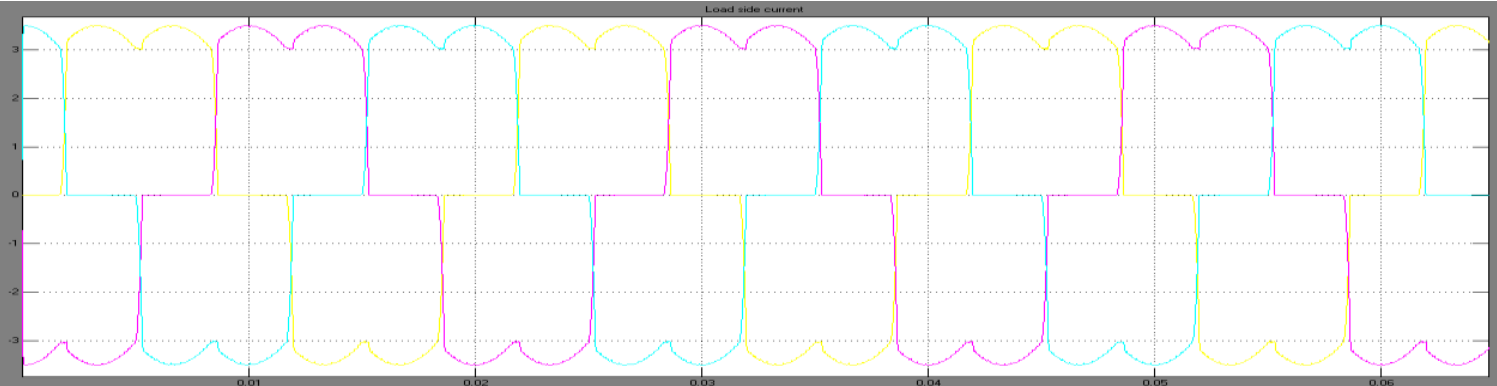

Fig. 8(b): Load current waveform

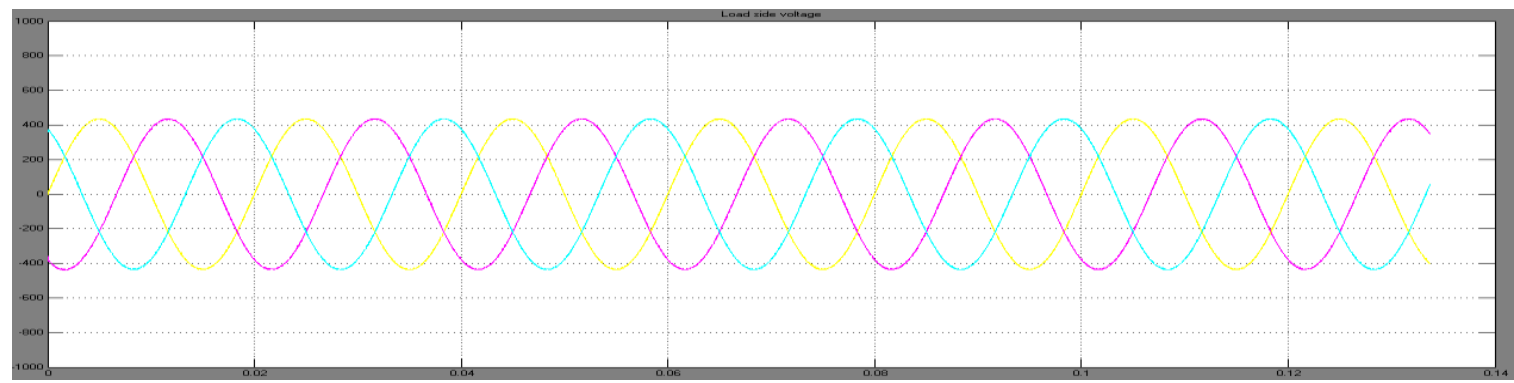

Fig. 8(c): Load voltage waveform 


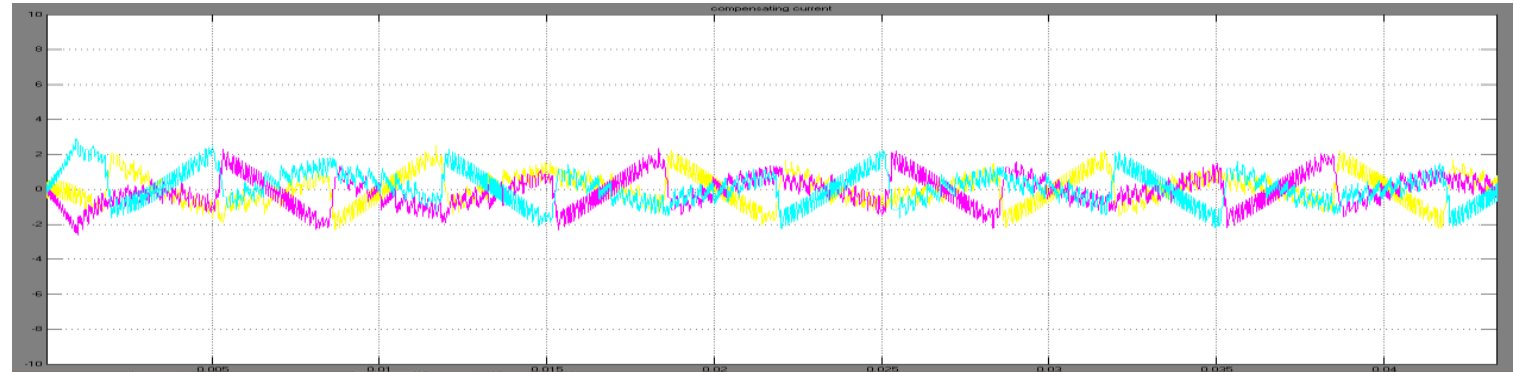

Fig. 8(d): compensating current waveform

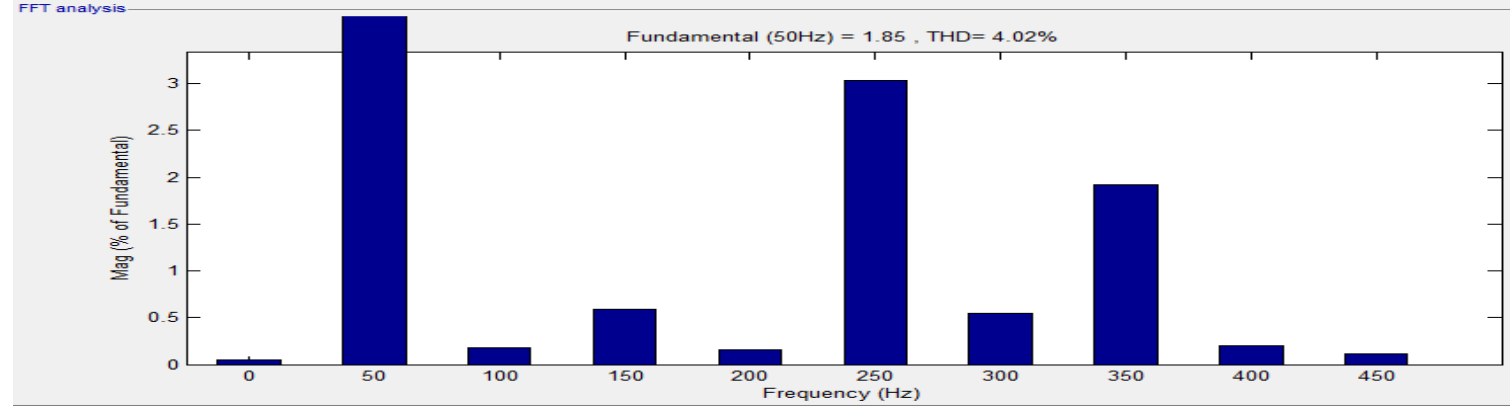

Fig. 8(e) current THD analysis

C. Simulation circuit with compensation using SPWM and PI with d-q technique

SPWM will work with variation in the modulation index of the sinusoidal wave which is compared with triangular wave for generating pulses. The fig.9 shows the complete simulation circuit diagram

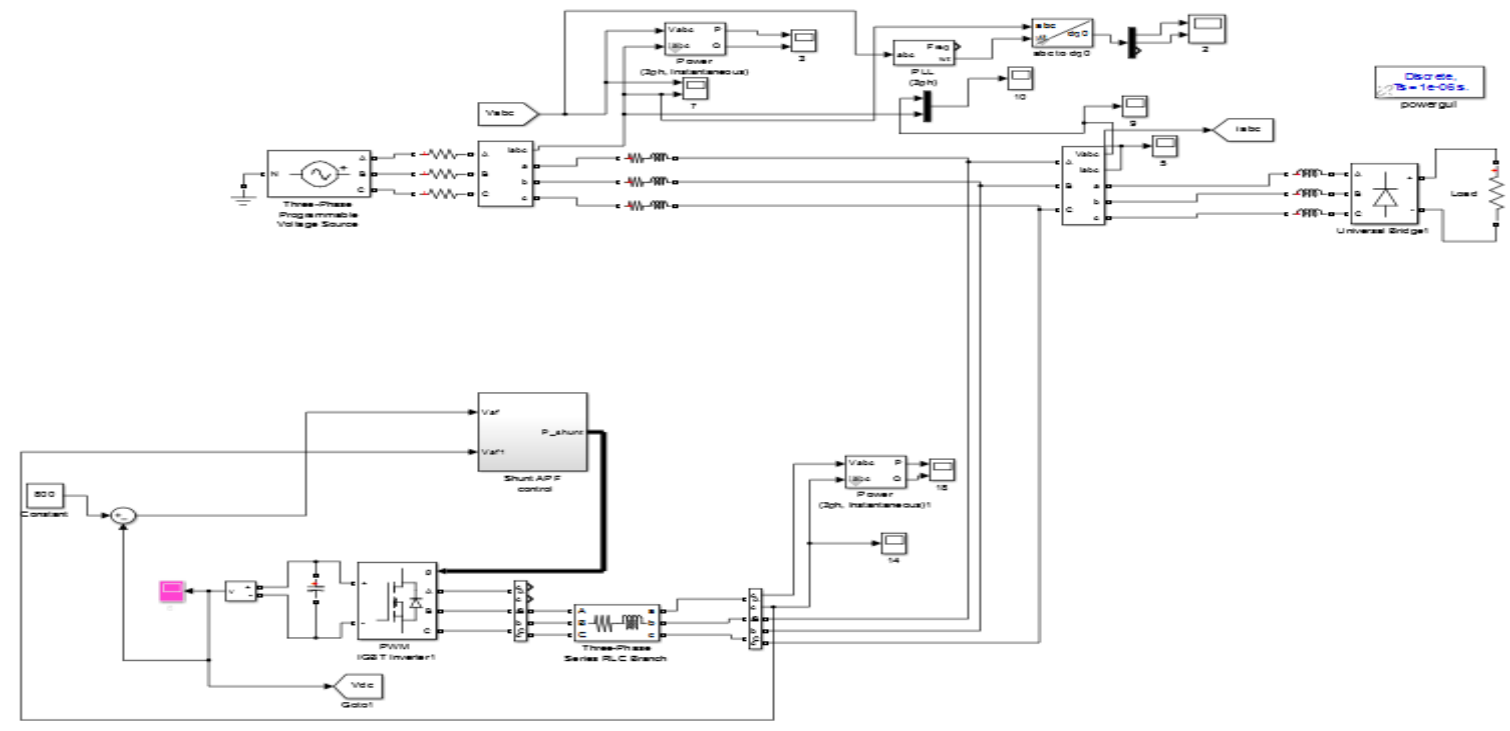

Fig. 9: Simulation circuit of SPWM and PI using d-q technique

(C)(i) Simulated output waveforms

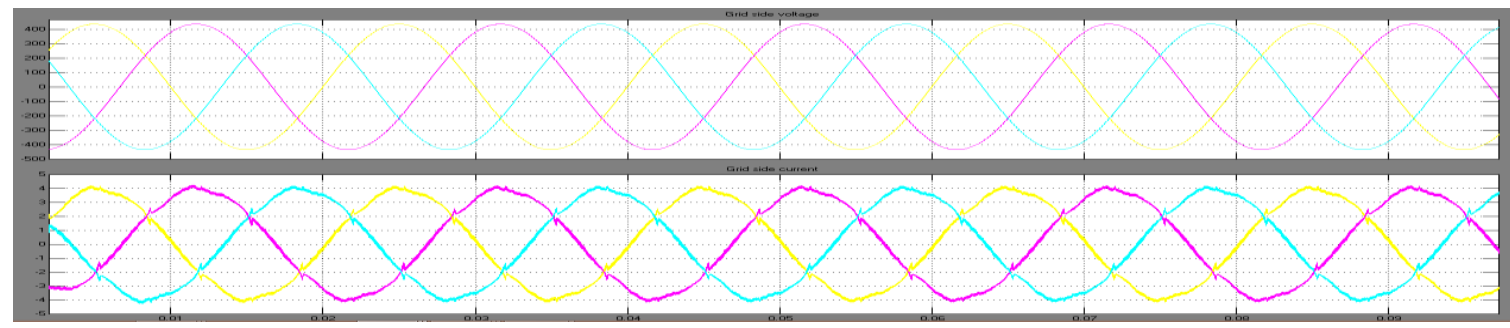

Fig. 9(a): 3 phase voltage and current waveform at grid side 


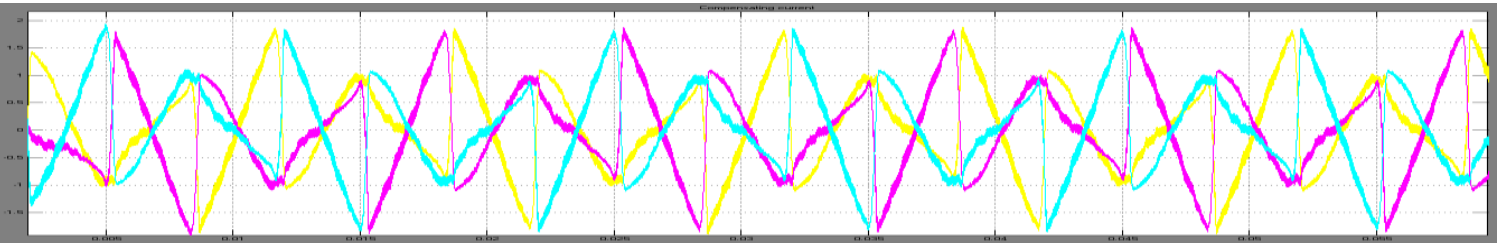

Fig. 9(b): compensating current waveform

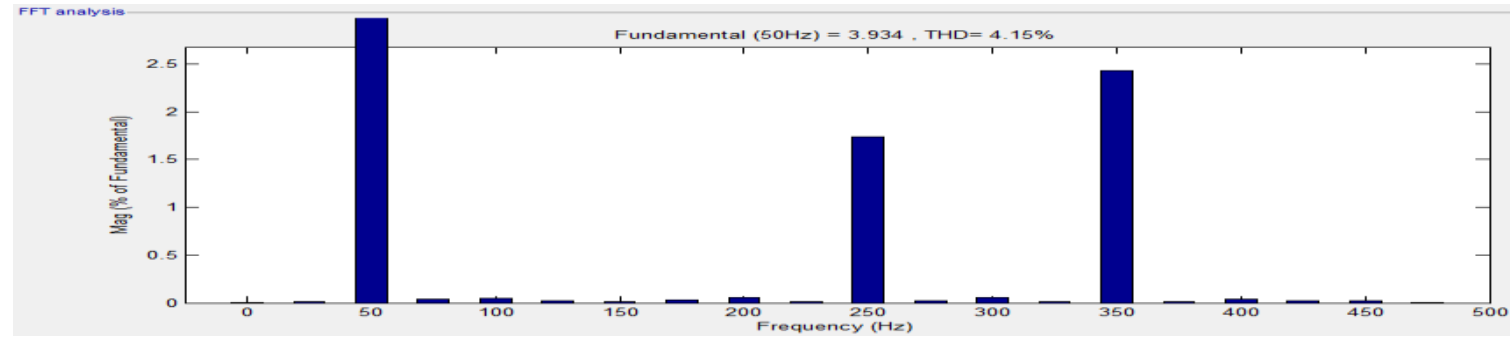

Fig. 9(c): current THD analysis

D. Simulation circuit with compensation using current hysteresis and PI with p-q technique

The compensating current will generate a pure sinusoidal wave in the source side. The fig. 10 shows the complete simulation circuit diagram.

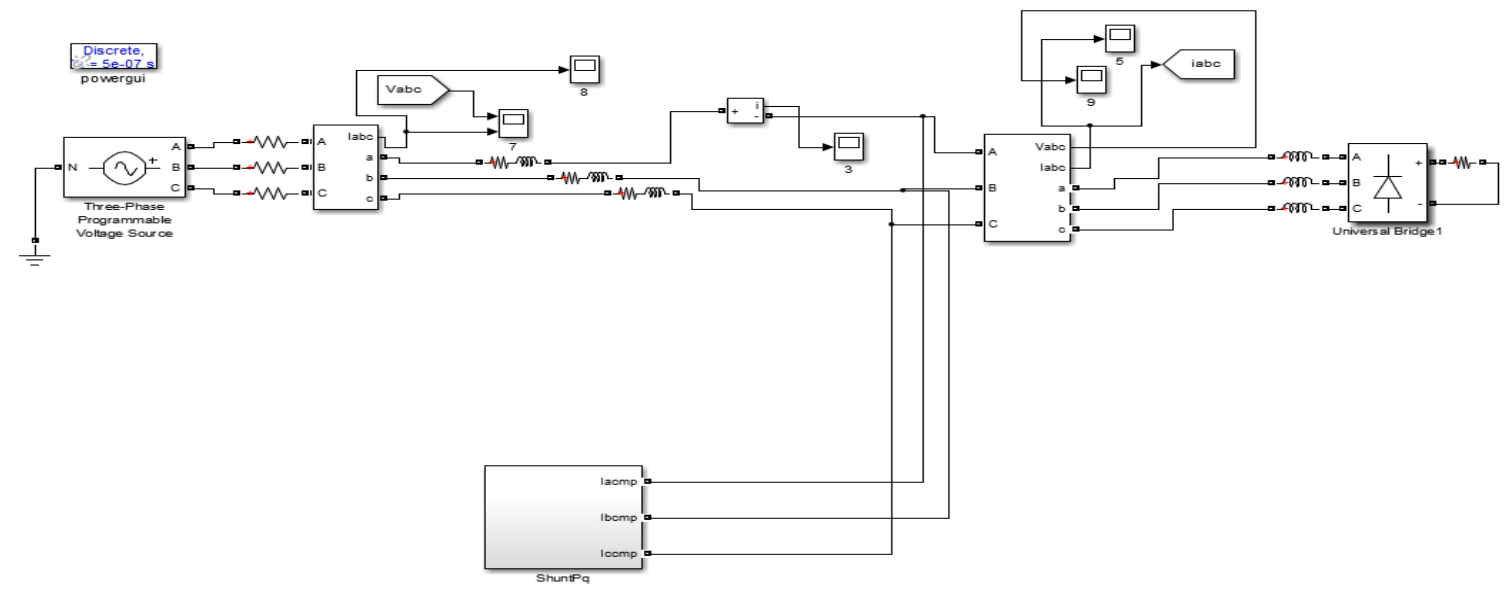

Fig. 10: Simulation circuit of current hysteresis and PI using p-q technique

(D)(i) Simulated output waveforms

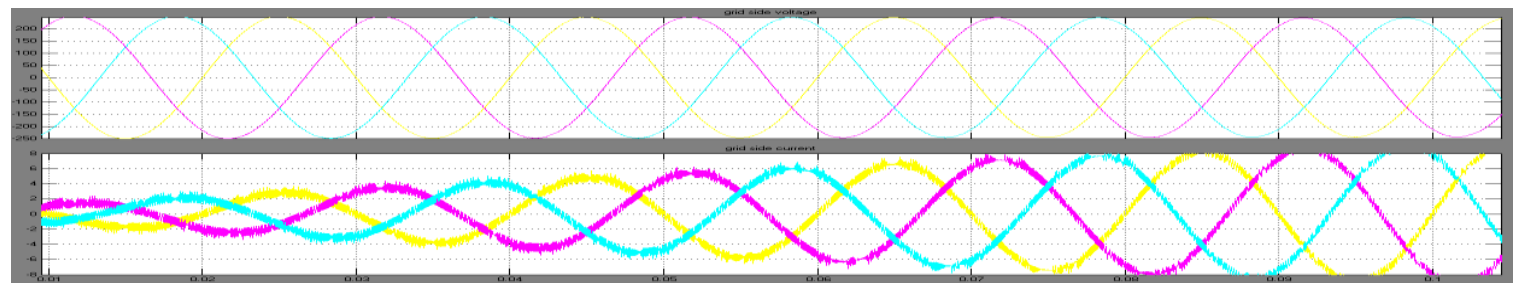

Fig. 10(a): 3 phase voltage and current waveform at grid side

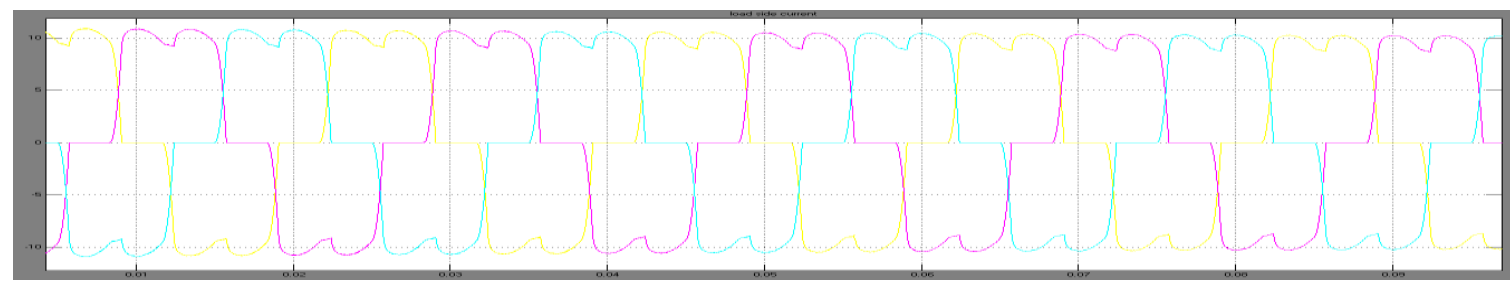

Fig. 10(b): Load current waveform 


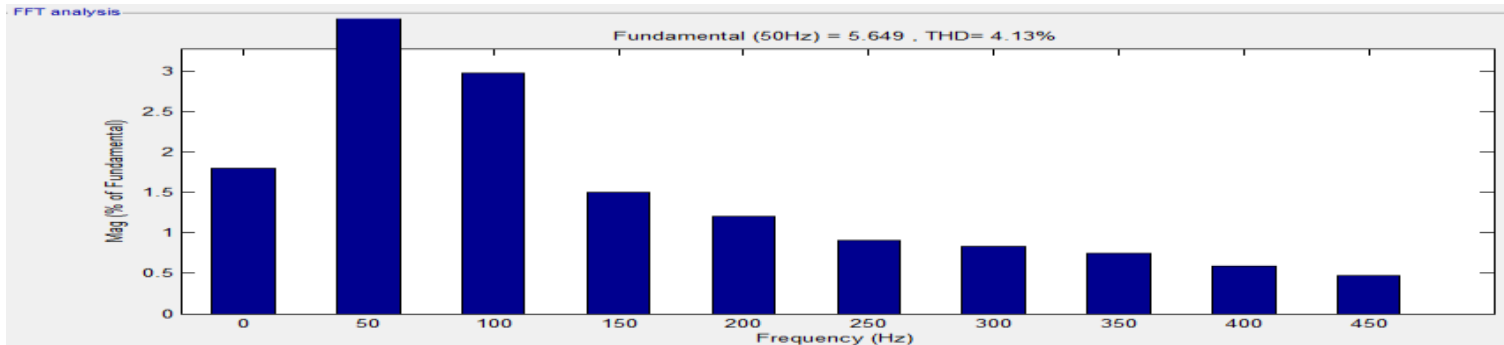

Fig. 10(c): current THD analysis

E. Simulation circuit with compensation using SPWM and PI with p-q technique

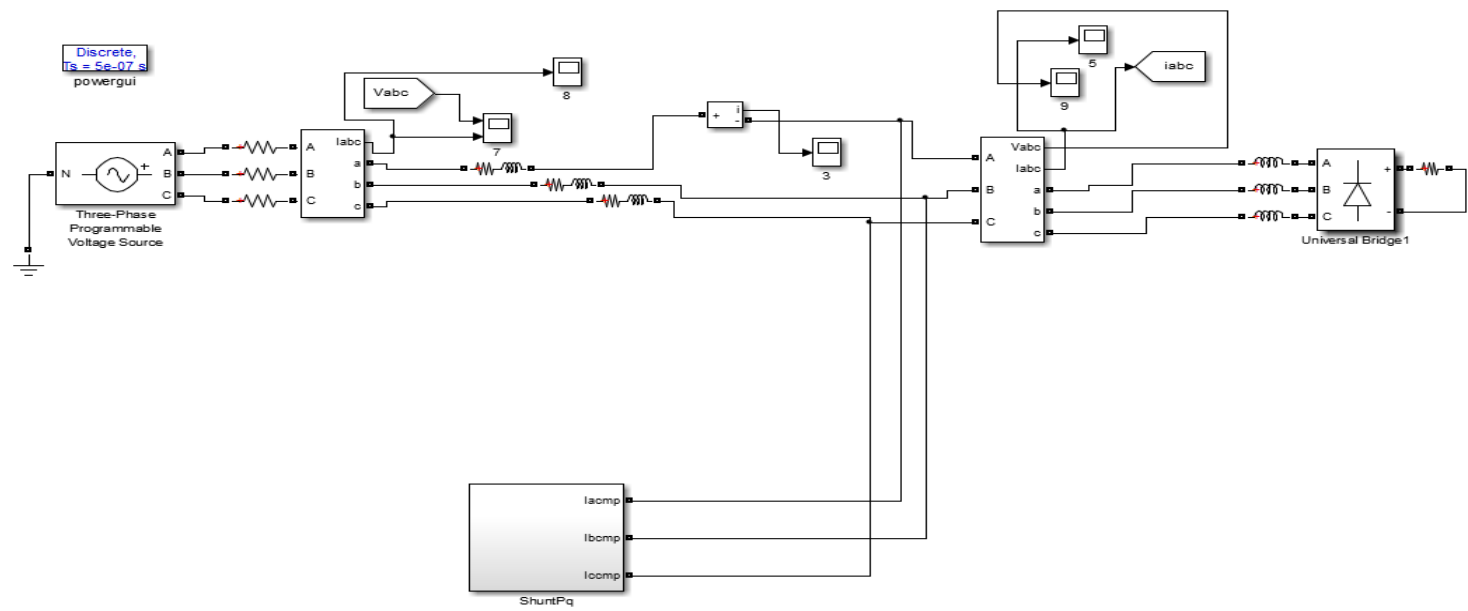

Fig. 11: Simulation circuit of SPWM and PI using p-q technique

(E)(i) Simulated output waveforms

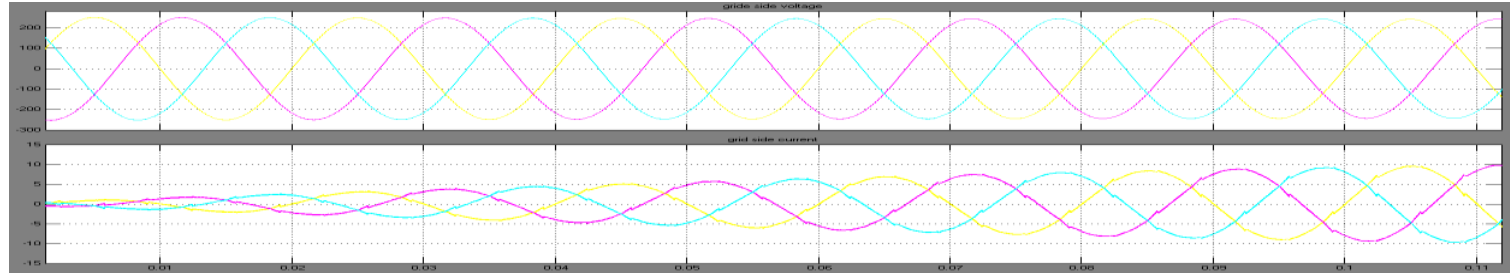

Fig. 11(a): 3 phase voltage and current waveform at grid side

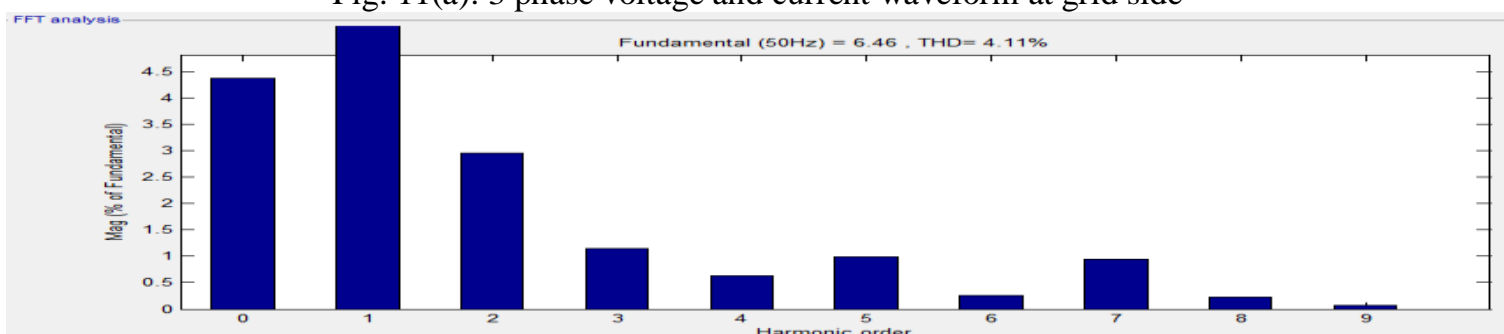

Fig. 11(b): current THD analysis

Table 2: Comparison of with APF and without APF

\begin{tabular}{|l|l|}
\hline METHODS & \% THD \\
\hline D-Q Method With Current Hysteresis & $4.02 \%$ \\
\hline D-Q Method With SPWM & $4.15 \%$ \\
\hline P-Q Method With Current Hysteresis & $4.13 \%$ \\
\hline P-Q Method With SPWM & $4.11 \%$ \\
\hline Without A.P.F & $24.68 \%$ \\
\hline
\end{tabular}




\section{IJIREEICE \\ International Journal of Innovative Research in Electrical, Electronics, Instrumentation and Control Engineering \\ ISO 3297:2007 Certified \\ Vol. 5, Issue 6, June 2017}

\section{IV.CONCLUSION}

The THD analysis of different A.P.F methods using $p-q$ and $d-q$ techniques were carried out using the MATLAB tools. The MATLAB Simulink based simulation is developed and tested for reactive power and THD. The THD observed for the proposed system with A.P.F using d-q and p-q method is reduced around 400\% from the THD that is observed for the non- compensating power system. It is also observed that the reactive power is also compensated.

\section{REFERENCES}

[1] Fuchs, E.F. and Masoum, M.A.S. ; "Power Quality in Power System and Electrical Machines," Elsevier, 2009.

[2] Moreno-Munoz, A. ; "Mitigation Technologies in a Distributed Environment," Springer, 2010.

[3] Singh, B. , Chandra, A. and Al-Haddad, K. ; “A Review of Active Filters for Power Quality Improvement," IEEE Transactions on Industrial Electronics, Vol. 46, No. 5, pp.1-12, 1999, doi: 10.1109/41.793345.

[4] Chelladurai, J. ,Ilango, G.S. , Nagamani, C. and Kumar, S.S. ; "Investigation of Various PWM Techniques for Shunt Active Filter," World Academy of Science, Engineering and Technology, Vol. 2, No.3, pp.173-179, 2008.

[5] Muthazhagi, M. and Kumar, N.S. ; "Comparison of Controllers for Power Quality Improvement Employing Shunt Active Filter," International Conference on Computing, Electronics and Electrical Technologies(ICCEET), pp.248-253, 2012, doi: 10.1109/ICCEET.2012.6203816.

[6] Peng, F.Z. ,Akagi, H. and Nabae, A. ; "Study of Active Power Filters Using Quad Series Voltage Source PWM Converters for Harmonic Compensation," IEEE Transactions on Power Electronics, Vol.5, No.1, pp.9-15, 1990, doi: 10.1109/63.45994.

[7] Kalaignan, T.P. and Raja, T.S. ; "Harmonic Elimination by Shunt Active Filter Using PI Controller," IEEE International Conference on Computational Intelligence and Computing Research(ICCIC), pp.1 -5, 2010, doi: 10.1109/ICCIC.2010.57055800.

[8] Jain, S. ; "Modelling and Simulation using MaTLAB-Simulink,” Wiley-India, 2013.

\section{BIOGRAPHIES}

Shivayogi Talagalamani completed B.E in EEE from TCE, Gadag in 2015 and pursuing M.tech (Power Electronics) in the Oxford College of Engineering, Bengaluru from 2015-2017.His area of interest are power electronics, power system, power quality, renewable energy, and control system.

Sandhya.P graduated from KVGCE, Sullia, Karnataka, India, in 1997 and obtained M.Tech in power electronics from BMSCE, Bengaluru, India, in 2008. She is currently pursuing Ph.D., under VTU and working as Associate Professor, in the Department of EEE, The Oxford College of Engineering, Bengaluru, since 2001. Her area of interest are power electronics, power system, power quality, and control system. 